\title{
VIVÊNCIA TEÓRICO-PRÁTICA INOVADORA NO ENSINO DE ENFERMAGEM
}

\author{
Theoretical and practical experience with an innovative approach to nursing education \\ Experiencia teórica y práctica de la enseñanza innovadora de la enfermería
}

\author{
Dirce Stein Backes ${ }^{1}$ \\ Adriana Dall 'asta Pereira ${ }^{4}$
}

\author{
Maristel Kasper Grando²
}

Juliana Silveira Colomé ${ }^{5}$
Michelle da Silva Araújo Gracioli ${ }^{3}$

Maria Helena Gehlen ${ }^{6}$

\section{RESUMO}

Os cursos de enfermagem vêm investindo em inovações no processo formativo, apostando em metodologias ativas e problematizadoras, que ofereçam ao acadêmico vivências na realidade social. Objetiva-se relatar a vivência de ensino-aprendizagem vinculada a um projeto ampliado de ensino, pesquisa e extensão fundamentado nas teorias de enfermagem. Trata-se de um relato de experiência desenvolvida a partir de uma atividade teórico-prática, realizada por meio de visitas semanais de docentes e discentes de enfermagem às famílias em condições sociais, ambientais e econômicas vulneráveis. Os resultados mostram uma pedagogia ativa, dialógica e interativa, capaz de fomentar redes solidárias de cooperação e a promoção de ambientes polissêmicos, favorecidos pelas reflexões dos problemas sociais emergentes. Assim, instigar o protagonismo e empreendedorismo social na formação, a partir das teorias de enfermagem, significa desenvolver um conhecimento capaz de dialogar e integrar os diferentes saberes, pelo desenvolvimento de práticas em consonância com o exercício da cidadania e transformação social.

Palavras-chave: Modelos de enfermagem. Teoria de Enfermagem. Saúde da família. Cuidados primários de saúde. Enfermagem.

\begin{abstract}
Nursing courses have been investing in innovations in the education process, betting on active and problematizing methodologies, which offer the nursing students experiences in social reality. This study aims to report teaching and learning experiences linked to a broadened teaching, research and extension program based on nursing theories. This is a report of experiences developed through a theoretical and practical activity carried out by means of weekly visits of nursing teachers and students to families living in precarious socioeconomic conditions as well as in poor environmental situation. The results show an active, dialogic and interactive pedagogy capable of fostering solidarity networks of cooperation and promoting a polysemic environment favored by the reflections on the emerging social problems. Thus, inciting the protagonism and social entrepreneurship in education on the basis of nursing theories meaning developing knowledge capable to dialog and integrate the different learning experiences through the development of practices in consonance with the exercise of citizenship and social transformation.
\end{abstract}

Keywords: Models Nursing. Nursing Theory. Family Health. Primary Health Care. Nursing.

\section{Resumen}

Los cursos de Enfermería vienen invirtiendo en la innovación del proceso formativo, haciendo apuestas en metodologías activas y problemáticas que traigan y ofrezcan a los académicos experiencias de la realidad social. Se objetiva relatar la experiencia de enseñanza y aprendizaje junto a un proyecto amplio de sabiduría, investigación y extensión basado en las teorías de enfermería. Se trata de un informe de experiencia desarrollada a partir de una actividad teóricopráctica a través de visitas semanales de profesores y estudiantes de enfermería a las familias adoptadas, en condiciones sociales, ambientales y socioeconómicas difíciles. Los resultados muestran una enseñanza activa, dialógica e interactiva, capaz de fomentar las redes solidarias de cooperación y la promoción de ambientes polisémicos, favorecido por las reflexiones de los problemas sociales emergentes. Por lo tanto, inculcar el protagonismo y el espíritu emprendedor social en la formación, a partir de las teorías de la enfermería, significa desarrollar un conocimiento capaz de dialogar e integrar los diferentes conocimientos, por el desarrollo de prácticas en consonancia con el ejercicio de la ciudadanía y la transformación social.

Palabras Clave: Modelos de Enfermería. Teoría de Enfermería. Salud de la Familia. Atención Primaria de Salud. Enfermería.

\footnotetext{
'Doutora em Enfermagem pelo Programa de Pós-Graduação de Enfermagem da UFSC, com doutorado Sanduíche na Universität Bielefeld/Alemanha. Docente do Curso de Enfermagem da UNIFRA/RS e Colaboradora do Programa de Pós-Graduação de Enfermagem da FURG. Líder do Grupo de Estudos e Pesquisa em Empreendedorismo Social da Enfermagem e Saúde/GEPESES. Santa Maria - RS. Brasil. E-mail: backesdirce@ig.com.br; ${ }^{2}$ Mestre em Enfermagem. Curso de Enfermagem do Centro Universitário Franciscano - UNIFRA. Santa Maria - RS. Brasil. E- mail: maristelgrando@hotmail.com; ${ }^{3}$ Mestre em Enfermagem. Curso de Enfermagem do Centro Universitário Franciscano - UNIFRA. Santa Maria - RS. Brasil. E-mail: michelle@unifra.br; ${ }^{4}$ Mestre em Enfermagem. Curso de Enfermagem do Centro Universitário Franciscano - UNIFRA. Santa Maria - RS. Brasil. E-mail: adrianadap@terra.com.br; ${ }_{5}^{5}$ Doutoranda em Enfermagem do Programa de Pós-Graduação de Enfermagem da FURG. Curso de Enfermagem do Centro Universitário Franciscano UNIFRA. Santa Maria - RS. Brasil. E-mail: julianacolome@yahoo.com.br; ${ }^{6}$ Mestre em Educação. Curso de Enfermagem do Centro Universitário Franciscano - UNIFRA. Santa Maria - RS. Brasil. E-mail: mahgehlen@terra.com.br
} 


\section{INTRODUÇÃO}

As instituições de ensino superior que objetivam uma educação proativa e inovadora, que busque atender às demandas sociais no campo da saúde, vêm investindo em mudanças no perfil dos novos profissionais de saúde. Para alcançar esse resultado, os discentes precisam estar continuamente envolvidos em ações que instiguem uma postura ativa diante do mundo, da profissão e da vida. Além disso, que possibilitem a expressão de suas singularidades e potencialidades como dispositivos para maior iniciativa, motivação, postura crítica diante dos obstáculos emergentes nos cenários teórico-práticos, bem como para a busca de alternativas na construção de projetos em consonância às necessidades de saúde individuais e coletivas.

0 processo de formação dos profissionais da saúde, articulado com as práticas sociais emancipadoras e transformadoras, está relacionado a uma abordagem de continuidade e de ruptura, ou seja, a continuidade do processo de evolução do mundo, das fronteiras, das tecnologias, dos estilos de vida que hoje requerem flexibilidade e criatividade dos trabalhadores, bem como a ruptura com as práticas pedagógicas que não capacitam os indivíduos para o agir diante da complexidade das situações do cotidiano ${ }^{1}$.

Nessa perspectiva, os cursos de graduação em enfermagem são instigados a investir na inovação metodológica do processo formativo, apostando em metodologias ativas e problematizadoras, que ofereçam ao enfermeiro vivências na realidade social. Nesta perspectiva, a Enfermagem, caracterizada como disciplina teórico-prática, possui potencial para fomentar ideias inovadoras, desencadeando em alguns profissionais a motivação para novas experiências. 0 ser e fazer enfermagem, dessa forma, necessita estar subsidiado em bases que possibilitem tanto a geração de novas teorias, como a reformulação dos modelos por elas utilizados, potencializando a tomada de decisões e a execução qualificada na Enfermagem nos diferentes espaços de inserção profissional².

Desse modo, o conhecimento e a utilização das teorias de enfermagem precisam ser cada vez mais incorporados como subsídio fundante de toda e qualquer ação, prática e intervenção no campo profissional da enfermagem. Justamente são elas que circundam e dão visibilidade ao ser/fazer da profissão, diferenciando-a do cuidado prestado por outras categorias profissionais. Assim, a organização de modelos explicativos e reformulações de teorias na enfermagem, relacionados com a aplicação e adaptação às culturas locais e diferentes realidades, são cada vez mais necessárias, pois oferecem base teórica para atuar no contexto sócio-histórico e auxiliam o profissional no enfrentamento das transformações do mundo contemporâneo.

Por isso, o ensino superior assume papéis que vão muito além de formar um bom profissional técnico e cientificamente competente. Constitui-se, gradativamente, em um processo complexo, no qual devem ser consideradas as diferentes dimensões do ser humano, aspirações e expectativas singulares, bem como o seu contexto real, a fim de lidar com as dúvidas, certezas e incertezas, ordem e desordem, ambiguidade e outros aspectos relacionados à construção do conhecimento ${ }^{3}$.

Em uma perspectiva metodológica inovadora, o ensino de enfermagem do Centro Universitário Franciscano (UNIFRA) busca um processo educativo articulado às Diretrizes Curriculares Nacionais do Curso de Enfermagem, ou seja, uma formação profissional que prepare o egresso para os desafios das transformações da sociedade, do mercado de trabalho e da atuação profissional. Ainda, conforme as diretrizes, busca fomentar competências técnicas, ético-políticas e administrativas no sentido de contemplar as necessidades sociais de saúde, o sistema de saúde brasileiro, o trabalho em equipe e a atenção integral ${ }^{4}$.

No propósito de ampliação do olhar e formação de profissionais proativos, dinâmicos e capazes de lidar com a desordem e as incertezas da sociedade contemporânea, o Curso de Enfermagem da UNIFRA vem implementando uma proposta diferenciada de ensino, intitulada "Adotando famílias" em situação vulnerável. A ideia consiste em uma vivência acadêmica de adoção de uma família, fundamentada nas teorias de enfermagem, que se inicia no terceiro semestre do curso e se estende até os semestres finais, portanto, articulada às demais disciplinas do curso, de forma integrada ao currículo.

Nesse sentido, passou-se a considerar que o cuidado de enfermagem deve ir além de ações pontuais e assistencialistas e assumir uma atitude proativa, ao lidar estrategicamente com as famílias, com o objetivo de emancipálas como atores sociais. Entende-se, com esse pensar, que é preciso "estar junto com a família, estar presente, tendo por objetivo fortificar e fazê-las descobrir as potencialidades da família na condução de seu processo de viver/ser/estar saudável para além do aspecto biológico"5:16.

0 ensino, como contínuo processo educativo, tem a possibilidade de promover a aprendizagem dialógica ao desconstruir a linearidade e ordem do pensamento, transformando-se em aprendizagem significativa. Isso se torna possível no momento que o estudante se envolve de forma integral, com ideias, sentimentos, cultura evalores da sociedade e com a profissão, constituindo-se em um profissional humano e criativo, preparado para lidar com a multiplicidade e complexidade do cuidar em saúde. Assim, objetiva-se socializar uma vivência inovadora de ensino-aprendizagem vinculada a um projeto ampliado de ensino, pesquisa e extensão fundamentado nas teorias de enfermagem.

\section{METODOLOGIA}

Trata-se de um relato de experiência vinculado ao projeto "Adotando familias", realizado por estudantes do terceiro semestre do Curso de Enfermagem da UNIFRA, sob a supervisão dos docentes. Conforme a matriz curricular do curso, este projeto está inserido no terceiro semestre, que possui como eixo 
transversal a "Integralidade do cuidado em saúde", com o propósito de desenvolver competências ético-políticas e socialmente responsáveis, pela adoção de famílias em situação social, ambiental e econômica vulnerável. As disciplinas do referido semestre, tais como Teorias de Enfermagem, Saúde Coletiva na Enfermagem, Semiologia e Semiotécnica e Desenvolvimento Profissional III, articulam-se e fundamentam o projeto ampliado que está inserido na comunidade há três anos e que visa emancipar a família como protagonista da sua história.

A cada semestre, novas famílias são adotadas e recebem acompanhamento dos acadêmicos em visitas semanais, sob supervisão docente. As famílias residem em uma região vulnerável, de um município do interior do estado do Rio Grande do Sul, considerada uma das maiores áreas de ocupação da América Latina, na qual a UNIFRA desenvolve práticas interdisciplinares de cuidado em saúde. A indicação das famílias é realizada pela equipe da Estratégia de Saúde da Família local e elencada por prioridades como a drogadição, o alcoolismo, a violência familiar, a prostituição infantil, as doenças crônicas, as doenças mentais, gravidez na adolescência, e outras.

Para sistematizar e fundamentar a proposta foi elaborado um fluxograma de ações, Figura 1, o qual evidencia a sistematização das diferentes etapas e as inter-relações estabelecidas com a vivência.

Figura 1: Sistematização da proposta teórico-prática com as famílias

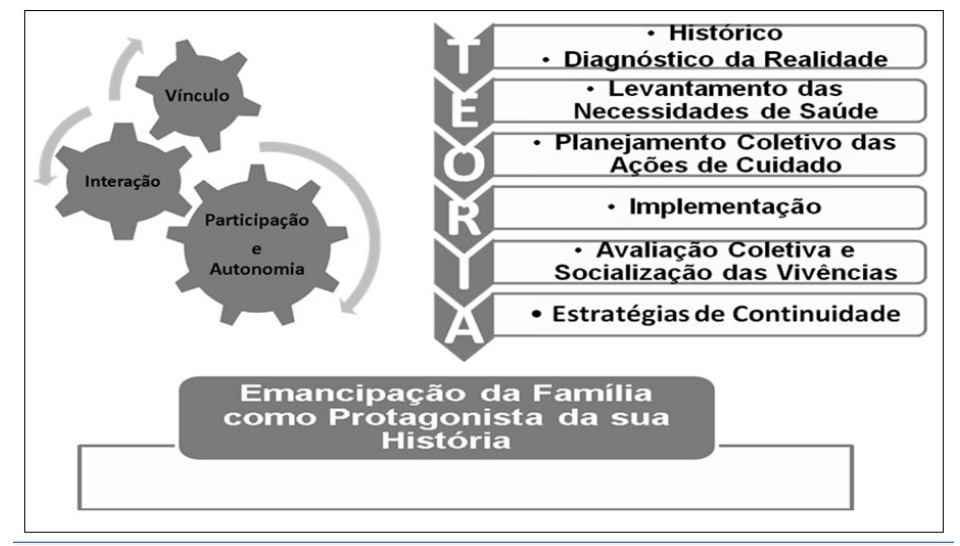

As etapas da atividade compreendem a realização do histórico da família e diagnóstico situacional, levantamento das necessidades de saúde, planejamento coletivo das ações de cuidado, implementação do plano de cuidados, avaliação coletiva e socialização das vivências, bem como a elaboração das estratégias de continuidade. Destaca-se que durante 0 desenvolvimento da proposta, as teorias de enfermagem serviram de apoio teórico e metodológico, selecionadas previamente e adequadas a cada realidade familiar ${ }^{6}$.

As teorias de enfermagem que serviram de base teórica para o desenvolvimento da atividade foram a Teoria do Autocuidado (Dorothéa Orem), Teoria Sistêmica (Rosalda Paim), Teoria das Necessidades Humanas Básicas (Wanda de Aguiar Horta), Teoria Ambientalista do Cuidado (Florence Nightingale), Teoria Interacionista (Joyce Travelbee), Teoria de Humanística (Josephine Paterson e Loretta T. Zderad) e Teoria da Adaptação (Sister Callista Roy).

A escolha das teorias se deu a partir das necessidades das famílias, com base em discussões coletivas entre docentes e estudantes, tanto em sala de aula quanto na comunidade. 0 relato da vivência apresenta as experiências adquiridas pelos docentes, discentes e pelas famílias, que participaram ativamente no delineamento de ações que atendessem às necessidades específicas de cada família. A criação de vínculos de confiança, a construção compartilhada e coletiva de todos os envolvidos, a interação efetiva e afetiva com a família foram resultados conquistados com esse trabalho.

As informações foram coletadas e analisadas de forma sistematizada, conforme descrito nas etapas do processo teórico-prático (Figura 1), que compreende o histórico e diagnóstico da realidade, o levantamento das necessidades, planejamento das ações de cuidado, implementação, avaliação coletiva, socialização da vivência e o delineamento de estratégias de continuidade.

\section{RESULTADOS}

\section{A experiência no olhar dos docentes}

0 contato com o cotidiano social das famílias constituiuse em uma escola formadora não somente para os acadêmicos, mas também para os docentes, que seguros de suas verdades, sentiram-se impelidos e desafiados a reverem conceitos tradicionais, bem como ampliarem as possibilidades interativas e de atuação da prática profissional do enfermeiro, para os diferentes espaços e contextos. 0 repensar valores, o respeito às diferentes culturas e saberes, o aprender na e com a diversidade destacaram-se como grandes experiências para os docentes, exigindo a mudança no modo de pensar e fazer tanto no ensino quanto na prática.

0 docente, enquanto mediador do protagonismo social dos acadêmicos com as famílias ocupa um papel privilegiado e, ao mesmo tempo, complexo pelo contato direto com o diferente 


\section{Vivência inovadora no ensino de enfermagem}

e o desconhecido. Situações de conflitos familiares, condições precárias de vida, drogadição, desemprego e perspectivas de vida pouco otimistas causaram, por vezes, sentimentos de confusão e insegurança nos docentes, demonstrando que as respostas para os problemas precisam ser soluções construídas no coletivo.

0 trabalho com as teorias de enfermagem revelaram que o saber-ser e o saber-fazer docente se integram às múltiplas possibilidades interativas e associativas de conhecer, ou seja, 0 real contexto das famílias e comunidades, tendo em vista que teorizar é instigar o novo e o diferente a partir da apreensão do conhecimento, transformando espaços, tempos, relações e métodos de ensino, e estimulando os acadêmicos a refletirem sobre as suas próprias condições de vida e o papel que desempenham na sociedade.

As teorias de enfermagem foram norteadoras neste processo de ensino aprendizagem e provocaram mudanças na comunidade, possibilitando, ao mesmo tempo, uma reflexão que exigiu saberes, desejo e sentido dos docentes e acadêmicos para a compreensão e transformação da realidade, o que contribuiu na construção de significados de qualidade na integração no semestre.

Nesse processo, o docente ocupa um papel importante, enquanto mediador e facilitador, principalmente no que diz respeito à sistematização das atividades teórico-práticas, mesmo que se constitua em um papel desafiador. Mais que mediador, o docente se considera o principal instigador, pela possibilidade articuladora e dinamizadora do diferente, pelo uso de estratégias interativas e dialógicas, como a problematização, a socialização de vivências, articulação com a equipe de saúde, dentre outras, alicerçadas na vida das famílias e das comunidades.

Por isso, para que o aluno tenha uma postura proativa diante das questões de mundo e sociedade, o docente precisa investir nas metodologias ativas e empreendedoras durante 0 processo de formação profissional. Para tanto, reforça-se que 0 processo de formação docente necessita incluir aos temas protocolares, aspectos inovadores e socialmente responsáveis, como processo grupal, questões relacionais, atividades em equipes multiprofissionais, apenas para enumerar alguns. A inclusão de saberes da música, da dança, da arte, do cinema, do teatro, do esporte e viagens também pode contribuir para a formação de um docente humano e eticamente responsável.

\section{A experiência no olhar dos discentes}

A proposta de intervenção comunitária foi apresentada aos acadêmicos de enfermagem como atividade teórico-prática, fundamentada nas teorias de enfermagem, previamente selecionadas e adequadas a cada realidade familiar. Inicialmente, a atividade despertou nos discentes um estado de confiança, alegria, espontaneidade e entusiasmo, indicando que para aprender é necessário construir um ambiente aberto e flexível à mudança, no sentido de superar a concepção tradicional e reducionista como tarefa difícil e cansativa.
No decorrer do processo, as diferentes vulnerabilidades da maioria das famílias foram gerando dúvidas, medos, incertezas e, principalmente, a sensação de impotência diante do desconhecido. No cotidiano, os discentes se depararam com situações reais de vida familiar, que foram, ao mesmo tempo, contraditórias, antagônicas e incertas. A realidade das famílias provocou sentimentos e vivências que, até então, haviam sido acompanhadas, em muitos casos, apenas por meio da mídia local.

As diferenças culturais, o choque de valores e a insegurança face ao novo possibilitaram, além de um contato e diálogo com a realidade concreta dos sujeitos em situações vulneráveis, o repensar dos valores e saberes, considerados como verdades absolutas e inquestionáveis.

A vivência discente os colocou diante das situações que instigaram o exercício do pensamento crítico, a tomada de decisão e o exercício da cidadania. Entenderam que a arte de aprender e ensinar se faz com uma postura sensível, atenta, acolhedora e ética, apresentando-se como pessoa de referência tanto nos saberes técnico-científicos quanto nos saberes relacionados à solidariedade, indicando que um profissional empreendedor procura, em condições menos favoráveis, fazer mudanças e provocar transformações. Além disso, diante de novas propostas ou ideias, desenvolvem pesquisas e procuram implementá-las e avaliá-las.

Assim, incorporar o pensamento crítico-reflexivo, contemplado no currículo do curso, constitui-se em um movimento dinâmico e permanente de articulação às tendências formativas preconizadas nas Diretrizes Curriculares Nacionais da Graduação em Enfermagem. Gradativamente os sentimentos iniciais de motivação, 0 clima de aceitação dos limites impostos, a responsabilidade e o comprometimento foram retornando, a partir dos resultados conquistados com as famílias, traduzindo-se em experiência gratificante e transformadora.

Para isso, potencializar a automotivação e a tranquilidade emocional fortalece a formação de um profissional capaz de construir o próprio caminho, mais seguro de seu potencial criador, com mais autoestima, autonomia e motivação, capaz de intervir e construir o próprio futuro, a partir da desordem daquilo que se aprende dentro e fora da sala de aula.

\section{A experiência no olhar das famílias}

As famílias que receberam o acompanhamento foram indicadas pela equipe da Estratégia de Saúde da Família local, escolhidas a partir das necessidades sociais e de saúde, como a drogadição, o alcoolismo, o desemprego, a violência, dentre outros. No transcorrer do período, inúmeras outras necessidades foram desveladas e anunciadas pelas próprias famílias, em que os discentes puderam auxiliar na busca compartilhada de soluções. 
As complexas necessidades apresentadas pelas famílias transcendem, portanto, o papel do profissional de saúde, exigindo uma postura de co-responsabilidade, superando a condição de detentor do saber. Evidenciou-se, que é preciso, junto com a família, descobrir meios que possam for tificá-la, mobilizá-la, impulsioná-la ao alcance de seu próprio equilíbrio e bem-estar.

A falta de saneamento básico, famílias numerosas em espaços impróprios e sem privacidade, ausência de condições mínimas de higiene e alimentação, renda insuficiente para 0 sustento da família foram algumas das várias questões encontradas e que, imediatamente, remeteram ao conceito ampliado de saúde da Constituição Federal de 1988.

Nessa direção foram encaminhadas algumas ações à unidade de saúde local, Secretaria Municipal de Saúde, laboratórios de práticas da UNIFRA, por meio dos diferentes cursos de graduação, bem como articulação com empresas privadas e Organizações Não Governamentais.

No entanto, muitos avanços foram percebidos nas famílias, os quais foram provocados pela vivência, como 0 auxílio no enfrentamento do luto familiar, a conquista de emprego, a conquista da casa própria, o batismo de gêmeos apadrinhados por um grupo discente, a realização de festas comemorativas em datas juninas e natalinas, a restituição dos vínculos familiares com a ressignificação do contexto de vida e do lar e o forte vínculo construído entre famílias, discentes e docentes. Dentre as ações desenvolvidas destacam-se o cuidado de si e do outro, a identificação dos fatores de risco para 0 adoecimento, 0 fortalecimento da rede de relaç̃̃es sociais, o apoio e estímulo ao enfrentamento das dificuldades vivenciadas no cotidiano, ampliação e for talecimento das ações realizadas e o estímulo às ações multiprofissionais.

Os resultados e perspectivas geradas com a proposta, a partir da avaliação das famílias, manifestaram interesse pela sua continuidade e sobre a importância de estendê-la a outras famílias ainda não assistidas. Do mesmo modo, apareceu a necessidade de continuidade do acompanhamento de algumas famílias que ainda não conseguiram melhorias significativas em sua condição familiar.

\section{DISCUSSÃO}

Avivência da adoção de familias instiga, portanto, à religação dos saberes, a partir do reconhecimento dos problemas reais do mundo e mediante o diálogo aber to e franco com o diferente.

Desenvolver um processo educativo teórico-prático, sob o enfoque do empreendedorismo social, permite relativizar as verdades hegemônicas do saber tradicional, por meio do desenvolvimento de competências capazes de dialogar e integrar os diferentes saberes. Significa, em suma, protagonizar novas possibilidades de intervenção social, pelo desenvolvimento de práticas sociais proativas e comprometidas com a formação articulada e inserida na realidade social ${ }^{7-9}$.

As exigências da sociedade global e plural suscitam, crescentemente, novas formas de intervenção social, principalmente nos espaços aparentemente invisíveis. Nesse campo de discussões, portanto, também a universidade ocupa uma função importante. É pelos processos de ensino e de aprendizagem que o novo e o diferente devem ser instigados e buscados 9 . Desse modo, o docente é o principal mediador/ instigador, pela possibilidade articuladora e dinamizadora do diferente, pelo uso de estratégias interativas e associativas, alicerçadas na vida das famílias e das comunidades.

No processo de formação, a universidade aparece como espaço de outros sentidos e significações para o estudante, configurando-se simbolicamente em um lugar de segurança, apoio, estímulo, oportunidades, conquistas e rupturas. Pautada em valores humanos, éticos-políticos e ecológicos, espera-se da universidade um lugar que promova a integração dos diferentes saberes, pela valorização das singularidades humanas ${ }^{3,10}$.

As relações construídas com as famílias perpassam uma postura inovadora e humana no ser e fazer profissional do novo enfermeiro. Assim, a relação entre profissionais de saúde e famílias deve se pautar em uma relação diferenciada e única. Para tanto, o profissional precisa saber como o outro define a situação, conhecer a cultura do outro, colocar-se no lugar do outro, além disso, dialogar e interagir com o outro. Precisa entender o significado que a família atribui às suas experiências 5 .

É preciso, portanto, preparar-se para o mundo incerto e aguardar o inesperado. Acredita-se que o processo formativo dos estudantes envolve uma postura docente capaz de auxiliálos no enfrentamento dos obstáculos e a preparação para assumir a condução de sua vida, sabendo lidar com as incertezas, acasos, dissonâncias, (in)sucessos, (in)suficiências, fraquezas, enquanto questões próprias do humano. É preciso conceber o sujeito como aquele que dá unidade e invariância a uma pluralidade de personagens, de caracteres, de potencialidades ${ }^{10: 128}$.

Sob esse enfoque, as visitas domiciliares constituíram-se em uma significativa fonte de interação, bem como uma estratégia facilitadora para o repensar dos valores pessoais e profissionais, considerando que o ser humano se torna autônomo e autor da sua própria história à medida que transcende o próprio saber e/ou as verdades absolutas, ${ }^{11-12}$.

Sendo assim, docentes e discentes precisam encontrar um novo ponto de referência, capaz de superar as incertezas e as contradições sociais. Necessitam transcender modelos de ensino e aprendizagem reducionistas e buscar o novo pela construção de personalidades humano-interativas críticas, politicamente engajadas e socialmente transformadoras. Pressupõe, em outras palavras, passar de um ensino transmissivo para uma pedagogia ativa, dialógica e interativa, capaz de fomentar redes solidárias de cooperação e a promoção de ambientes polissêmicos, favorecidos pelas reflexões dos problemas sociais emergentes. 


\section{CONSIDERAÇÕES FINAIS}

0 trabalho de adoção de famílias como metodologia ativa e empreendedora na formação do profissional enfermeiro viabiliza a construção do conhecimento de forma inovadora e transformadora, pela valorização do diferente, do incerto e aleatório, voltado para a realidade concreta das famílias, tal como recomenda as diretrizes curriculares para o ensino da saúde. Pode ser concebido, também, como um modelo pedagógico que institui uma nova proposta formativa, capaz de ressignificar e reorganizar o saber, embasando novos referenciais, capazes de criar espaços educativos favoráveis à construção de sujeitos pensantes, solidários e protagonistas de uma nova sociedade.

A proposta metodológica de ensino adotada pelo curso de enfermagem sintetiza, em suma, um forte desejo docente de promover a aprendizagem significativa, pela possibilidade de transcender os espaços tradicionais da sala de aula. Acreditase que a formação de profissionais críticos, reflexivos e socialmente responsáveis perpassa pelo conhecimento e inserção acadêmica na complexidade dos problemas sociais, no sentido de ampliar as oportunidades e possibilidades empreendedoras dos diferentes atores envolvidos no processo.
8. Backes DS, Backes MS, Erdmann AL. Promovendo a cidadania por meio do cuidado de enfermagem. Rev Bras Enferm. 2009 maio/jun; 62 (3): 430-34.

9. Erdmann AL, et al. Formación de emprendedores en enfermería: promover capacidades y aptitudes sociopolíticas. Enferm Global. [citado 2008 jun 27]; 16 (1). Disponível em: http://revistas.um.es/eglobal/article/ view/66271/63891.

10. Morin E. A cabeça bem feita: reformar a reforma reforça o pensamento. $10^{a}$ ed. Rio de Janeiro: Bertrand Brasil; 2004.

11. Backes DS, Erdmann AL. Formação do enfermeiro pelo olhar do empreendedorismo social. Rev Gauch Enferm. 2009; 30(2): 242-48.

12. Backes DS, Marinho M, Costenaro RS, Nunes S, Rúpolo I. Repensando o ser enfermeiro docente na perspectiva do pensamento complexo. Rev Bras Enferm. 2010; 63 (3): 421-26.

\section{REFERÊNCIAS}

1. Silva MG, Fernandes JD, Teixeira GAS, Silva RMO. Processo de formação $\mathrm{da}(0)$ enfermeira (0) na contemporaneidade: desafios e perspectivas. Texto\&Contexto Enferm. 2010; 19(1): 176-84.

2. Costa LB, Costa AAS, Saraiva MRB, Barroso MGT. Aplicação de estruturas conceituais na consulta de enfermagem à família. Esc Anna Nery. 2007; 11 (3): 515-19.

3. Morin E. Os sete saberes necessários à educação do futuro. $8^{\text {a }}$ ed. São Paulo: Cortez; 2003.

4. Ministério da Educação(BR). Conselho Nacional de Educação. Resolução $n^{0}$ 03, de 07 de novembro de 2001. Institui diretrizes curriculares nacionais do curso de graduação em enfermagem. Brasília(DF). Diário da República Federativa do Brasil, Brasilia (DF), 09 nov 2001: Seção 1: 37.

5. Marcon SS, Elsen I. Os caminhos que, ao criarem seus filhos, as famílias apontam para uma enfermagem familial. Cienc Cuid Saude. 2006; 5 (supl.): 11-18.

6. Gehlen MH, Zamberlan C, Colomé J, Backes DS, Machado KFC. Processo educativo teórico prático na ótica de docentes de enfermagem. Anais do $62^{\circ}$ Congresso Brasileiro de Enfermagem; out 11-15; Florianópolis, Brasil. Florianópolis: ABEn; 2010. p. 7803-04.

7. Backes DS. Vislumbrando o cuidado de enfermagem como prática social empreendedora. [tese]. Santa Catarina: Programa de PósGraduação em Enfermagem, Universidade Federal de Santa Catarina; 2008. 